\title{
How the Interaction of Childhood Sexual Abuse and Gender Relates to HIV Risk Practices among Urban-Dwelling African Americans
}

\author{
Klein $\mathrm{H}^{* 1}$, Elifson $\mathrm{KW}^{2}$ and Sterk $\mathrm{CE}^{2}$
}

${ }^{1}$ Kensington Research Institute, Kensington MD and Rollins School of Public Health, Emory University, Atlanta GA, United States

${ }^{2}$ Rollins School of Public Health, Emory University, Atlanta GA, United States

${ }^{*}$ Corresponding author: Klein H, Kensington Research Institute, Kensington MD and Rollins School of Public Health, Emory University, Atlanta GA, United States, E-mail: hughk@aol.com

Citation: Klein H, Elifson KW, Sterk CE (2016) How the Interaction of Childhood Sexual Abuse and Gender Relates to HIV Risk Practices among Urban-Dwelling African Americans. J Aids Hiv Infec 2(1): 105. doi: 10.15744/2454-499X.2.105

Received Date: June 09, 2016 Accepted Date: August 30, 2016 Published Date: August 31, 2016

\begin{abstract}
Purpose: Previous research has demonstrated that HIV risk practices often differ based on gender and on whether or not people experienced sexual abuse during their formative (i.e., childhood and adolescence) years. The interaction of these two factors, which is the focus of this paper, has received limited attention.

Methods: Based on a model derived from Social Disorganization Theory and Syndemics Theory, interviews were conducted between 2009 and 2012 with 1,864 African American adults residing in Atlanta, Georgia in 80 strategically-chosen consensus block groups.

Results: Based on multiple regression and structural equation analyses, the interaction of sexual abuse and gender was found to be a significant predictor of involvement in (un)protected sex. The interaction of sexual abuse and gender also was related to condom use self-efficacy, which was one of the strongest factors underlying (un)protected sex.

Conclusion: The relationship of sexual abuse history and gender is relevant in the understanding of HIV risk practices. The interaction of these factors with one another and with other relevant influences that shape people's HIV risk profiles is complex. The Syndemics Theory approach used to conceptualize the relationships among relevant variables in this study is an effective way of trying to understand and address HIV risk practices.
\end{abstract}

Keywords: Childhood sexual abuse; Gender differences; HIV risk practices; Unprotected sex; African Americans

\section{Introduction}

Many studies have demonstrated that experiencing sexual abuse during one's childhood and/or adolescent years is associated with a variety of adverse outcomes that often extend well into adulthood. Psychologically, among the many types of consequences that have been shown to be associated with childhood sexual abuse are an increased risk for depression, an elevated risk for experiencing suicidal ideations and/or suicide attempts, diminished self-esteem, an elevated sense of anger or hostility, and the development of a more impulsive personality type [1-9]. Behaviorally, experiencing sexual abuse has been shown to be linked with such varied problems as the development of eating disorders, an elevated risk for victimizing and/or perpetrating violence against others, a greater tendency toward developing problems with alcohol and/or other drugs, an increased likelihood of developing a gambling problem, and an increased likelihood of engaging in risky sexual behaviors [10-18].

These various adverse outcomes have been reported among men and women alike, although most of the scholarly literature has focused on the long-term effects of sexual abuse among women. In fact, it is only during the past decade or two that much attention has been paid to childhood sexual victimization among males and how their experiences with earlier-life sexual abuse continue to affect them later in life [19-21]. Studies examining the differential impact of sexual abuse on males and females are rare in the scholarly literature, and little is known about how sexual abuse experiences may affect men and women differently [19,22]. One excellent exception to this is the work published by the Australian Institute of Family Studies [23].

Developing a better understanding of the specific ways in which gender and childhood sexual abuse interact with one another is likely to be very important, and a key way to further scientific knowledge in the field of childhood maltreatment. There is good reason to believe that gender and childhood sexual abuse experiences may interact in such a manner as to make certain population subgroups differently affected or more "damaged" than others. For example, it is possible that women who were sexually abused 
during their formative years (i.e., prior to reaching the age of majority) suffer more than never-abused women and/or their sexually-abused male counterparts. In relationship contexts, women often find themselves at a power disadvantage, in large part due to fears of domestic/partner violence, concerns about being abandoned financially, fears of being threatened emotionally or psychologically if they want something that is inimical to their partner's wishes, and so forth [24-26]. Among women who previously experienced sexual abuse, it is possible that the combination of their gender and childhood maltreatment experiences may leave them feeling incapable of asserting themselves when it comes to matters concerning their sexual health (e.g., insisting that any/all sexual acts with their male partners involve the use of protection, feeling comfortable and safe saying "no" to a sexual advance, openly discussing HIV and STI testing history). In recent years, there has been some research supporting this type of gender-by-sexual-abuse-history hypothesis [27,28].

As another, alternative possibility, it might be the case that sexually-abused African American men may fare worse than their never-abused and/or their female sexually-abused counterparts. It has been well-established that, in the African American community, there are widely-held masculinity norms in operation, establishing behavioral expectations for what men should and should not do, what men should and should not experience, and so forth [29-31]. These masculinity norms underlie many cultural expectations governing sexual behaviors among African American men [32-34]. Being sexually victimized runs counter to these masculinity norms, because they imply that the male victim is somewhat less of a man-that is, somewhat less manly-specifically because he was sexually abused [35]. In addition, gender norm expectations in the African American community are such that men are supposed/expected to be dominant in their relationships, and in control of the sexual aspects of their relationships and their lives [36]. Thus, African American men who have been sexually abused at some point during their lives may find themselves at odds with the African American community's expectations regarding strength, masculinity, dominion, gender norms, power, and so forth. This, in turn, may lead them to fare poorly compared to other gender-and-sexual-abuse-history groups when it comes to psychological functioning and/or involvement in risky behaviors. With so little research having been conducted to examine this issue, particularly as it pertains to African American men, we have limited knowledge about the ways in which gender and sexual abuse history are likely to influence one another.

Also limited in the scientific literature is research on the differential impact of sexual abuse experiences among different racial groups although admittedly, during the past decade, a number of studies have addressed the issue of sexual abuse among African American girls and women [2,37-40]. Even less is known about African American men and their experiences with sexual abuse. The NIMH Multisite HIV/STD Prevention Trial for African American Couples Group ${ }^{1}$ found that men who had been sexually abused during childhood were almost twice as likely to be HIV-infected as their never-abused counterparts, with the large majority of these men presumed to have been infected via unprotected sex [41]. Based on their research with Caucasian and African American boys raised in an urban area in Pennsylvania, Lee and colleagues found that, as young adults, African Americans who had been victims of childhood maltreatment were more likely to be violent offenders and more likely to suffer from depression than their Caucasian counterparts and their peers who had not been maltreated [42]. Otherwise, most of the published literature focusing on childhood sexual abuse among African American men has been based on samples of men who have sex with other men (see Footnote \#1, below).

Moreover, we believe that it is important to point out that, in addition to race and gender, a variety of other cultural, demographic, and community-related factors may have an effect upon sexual abuse and contribute to its impact upon people who are victimized. For example, research has shown a link between experiencing sexual abuse early in life and subsequently living in poverty or in a community that is characterized by high rates of poverty and/or unemployment $[43,44]$. Some research has taken this finding one step farther, by demonstrating that the sexual abuse $\rightarrow$ poverty nexus also extends to sexual abuse $\rightarrow$ poverty $\rightarrow$ HIV-related sexual risk practices such as prostitution and substance abuse [45]. Evidence is mixed as to the extent to which community-factors or neighborhood characteristics affect sexual abuse, with those authors specifically noting that this is an understudied area in the scholarly literature on childhood maltreatment [46].

In the present paper, we examine the interaction of gender and childhood sexual abuse in a community-based sample of African American adults living in an urban metropolitan area. Based on a conceptual model that owes its theoretical underpinnings both to Social Disorganization Theory and Syndemics Theory, this paper focuses on the following research questions: (1) How, if at all, do gender and sexual abuse history interact with one another when it comes to their influence on HIV risk taking? (2) How, if at all, do gender and sexual abuse history interact with one another when it comes to their influence on psychological functioning? (3) Does the interaction of gender and sexual abuse history contribute significantly to the overall prediction of people's involvement

${ }^{1}$ A few other studies have examined the impact of sexual abuse experiences on self-identified gay and bisexual African American males. Because men who have sex with other men (MSM) comprised only a small portion of the People and Places study sample, and because of cultural differences that strongly affect the behaviors of gay/bisexual men compared to their heterosexual counterparts, the results of these studies are being reported separately. One such study found that experiencing childhood sexual abuse increased men's likelihood of engaging in compulsive sexual behaviors in adulthood [99]. It also elevated their chances of experiencing depression and symptoms of anxiety. Welles and colleagues reported that African American MSM who had been sexually abused during childhood were more likely to be victims of intimate partner violence and to be perpetrators of intimate partner violence in their current relationships compared to those who had not been sexually abused [100]. Based on their qualitative research with three samples of African American MSM, Fields, Malebranche, and Feist-Price concluded that sexual abuse experiences during childhood led many of these men to experience depression, social isolation, suicidality, and "acting out" behaviors of various types [101]. Welles and colleagues' study of Caucasian, Latino, and African American HIV-positive MSM revealed that sexual abuse among African American men was associated with an increased number of sexual contacts and an elevated number of unprotected anal sex acts [102]. 
in HIV risk taking when the influence of other key factors such as demographic characteristics, substance use behaviors, sexual behaviors, and psychological/psychosocial functioning are taken into account? If so, which gender/sexual abuse history group(s) is/are most affected?

\section{Conceptual Model}

People and Places, the name of the study that served as the data source for the current paper, was based on a conceptual model (see Figure 1) that was derived from the tenets of Social Disorganization Theory and Syndemics Theory (for overviews of these theoretical approaches [47,48]). As Figure 1 depicts, for the "parent" study, drug use and risky sexual behaviors are hypothesized to be influenced by a variety of factors, including neighborhood-level structural characteristics (e.g., prevalence of poverty, prevalence of vacant housing, prevalence of female-headed households), observed physical and social disorder (e.g., presence of graffiti, accumulation of trash/litter in the neighborhood, presence of dysfunctional or abandoned vehicles), neighborhood perceptions (e.g., the perception that neighbors would intervene if children were truant and "hanging out," the belief that people in the neighborhood can be trusted, fear of living in a particular neighborhood), sociodemographic characteristics (e.g., age, household income, religiosity, educational attainment), social psychological characteristics (e.g., self-esteem, depression, personal support networks), and drug use situational characteristics (e.g., illegal drug use amongst members of one's social network, locations/ settings for illegal drug use, having sex while "under the influence"). Many of these influencing factors are hypothesized to interact with and to influence one another, helping to shape the "overall picture" of study participants' substance use/abuse or involvement in HIV risk behaviors. Some of the anticipated relationships are hypothesized to be causal and direct (indicated by solid lines on the figure), and others are hypothesized to be indirect or mediated by other variables in the model (indicated by dashed lines on the figure). The Social Disorganization Theory and Syndemics Theory paradigms underlying this conceptual model were selected for use in the People and Places study because both have been shown in previous studies to be effective and appropriate ways of conceptualizing the myriad factors that influence substance use/abuse and HIV risk practices [49-53]. In the present paper, emphasis is placed principally on the relationships and measures depicted in the four boxes on the right half of the page, as those shown on the left half of the page apply more to substance use/abuse outcome measures than they do to HIV risk behavior outcomes.

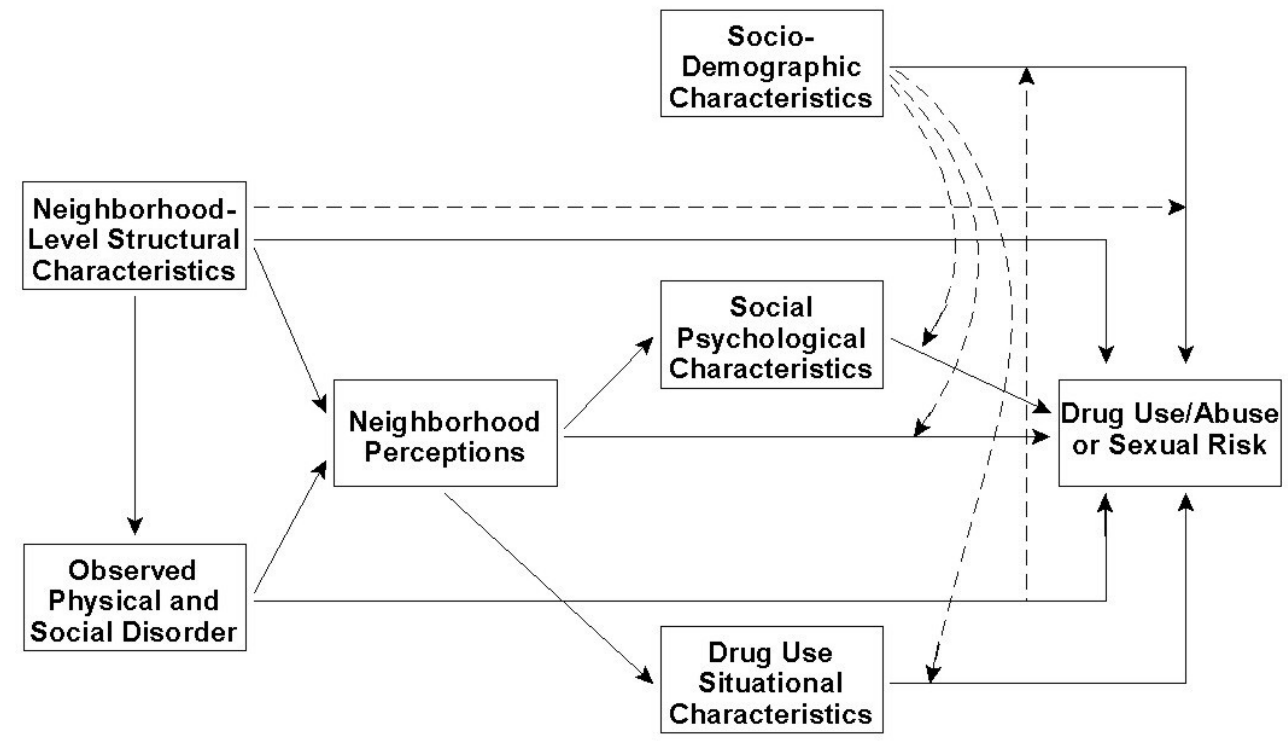

\begin{tabular}{|c|c|}
\hline Direct relationship hypothesized & Indirect relationship hypothesized \\
\hline
\end{tabular}

Figure 1: Conceptual Model for People and Places Study

Consequently, a more analysis-specific conceptual model, derived from the guiding theoretical models underlying the People and Places "parent study," was developed. That is shown in Figure 2. There, readers can see that the main outcome measure-which focuses specifically on HIV risk in the present paper-is construed as being affected by five types of other influences: demographic characteristics, sexual behavior practices, substance use/abuse behaviors, psychological and psychosocial functioning, and condom use self-efficacy. Most of these measures are also hypothesized to affect or to be affected by one another, too, as Figure 2 portrays. Consistent with the Syndemics Theory underpinnings for this research, it is the unique way that these factors influence one another and interact with one another that serves as the principal reason for adopting this conceptual approach to studying the research questions at hand. 


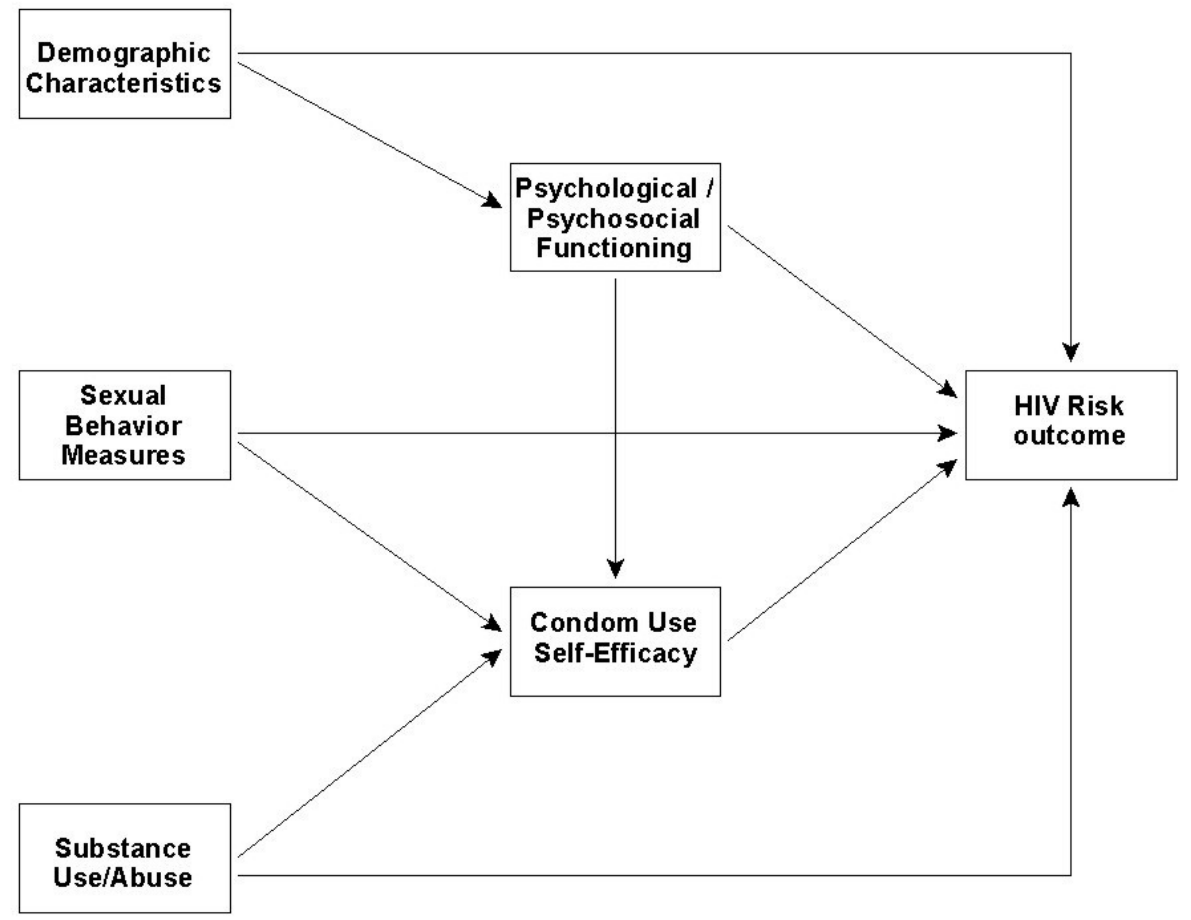

Figure 2: Conceptual Model for the Present Paper

\section{Methods}

\section{Procedures}

The data for this paper were collected as part of People and Places, a cross-sectional, community-based study of people's perceptions of how their neighborhood perceptions and contexts impacted their daily lives and actions, specifically their health and wellbeing. Data were collected between May 2009 and March 2012 in Atlanta, Georgia. Participants $(n=1,864)$ were recruited from 80 census block groups, the residents of which largely were African Americans. Both active community outreach strategies (based on ethnographic information and interviews done with key informants) and passive methods (e.g., posting flyers in public places such as telephone poles, message boards inside of local bars, and message boards inside of some local stores) were used to recruit study participants. The census block groups included in the study were selected based on neighborhood structural characteristics as reported in the 2000 U.S. Census Data and based on data from the Atlanta Police Department. Consistent with the People and Places' conceptual model and previous research findings, the neighborhood structural characteristics were selected on the basis of seven specific criteria: (1) the percentage of household incomes that were reported to be more than $20 \%$ above or below the federal poverty level, (2) the percentage of adults who had not completed high school or its equivalent, (3) the percentage of female-headed households, (4) the percentage of people who were unemployed or not in the labor force, (5) the percentage of one-unit housing structures, (6) the percentage of owner-occupied households, and (7) the percentage of vacant housing [54,55]. Specifically relevant for the present paper, within the selected census block groups, the sampling frame was designed to ensure sufficient variability by gender. Additionally, within census block groups, respondents were sampled within a two to three month period to guard against variability in actual neighborhood changes that could influence people's perceptions.

In order to be considered eligible for participation, respondents had to self-identify as African American, be at least 18 years of age, and have lived in that same neighborhood or census block group continuously for at least one year ${ }^{2}$. People were considered ineligible for the study if they: (1) were in a drug treatment program or any other institutional setting for three months or longer during the year prior to interview, (2) were intoxicated at the time of consent or interview (see Footnote \#2, below), or (3) displayed signs of cognitive impairment at the time of consent or interview.

${ }^{2}$ Respondents who were deemed ineligible to participate at the time of their scheduled interview due to intoxication were given the option of rescheduling their interview at another time when they were not under the influence of alcohol and/or another drug. It should be noted that fewer than $5 \%$ of the respondents came to their initial interview while "under the influence," indicating that this was not a major problem in the People and Places study. All but two of those persons who were asked to come back at a later time when they were sober elected to do so. 
Individuals who met the eligibility criteria and who were interested in participating in People and Places were scheduled for an interview appointment at a research site situated within one of the communities included in the study ${ }^{3}$. Prior to the interview, which took place in a private room at the site, the interviewer explained the nature of the study, the time required for participating, and completed other informed consent-related procedures (see Footnote \#3, below). The respondents were informed that a certificate of confidentiality protected all study materials. Once participants demonstrated a clear understanding of the consent form, they were asked to sign it and were provided with a copy. The Emory University Institutional Review Board approved the study protocol prior to implementation of the research.

Computer-assisted structured interviews (CASI) were conducted with eligible persons. The survey included such domains as demographic characteristics, social-psychological characteristics, health history, victimization and abuse experiences during the formative years, sexual history, drug use history, criminal justice involvement, and neighborhood perceptions. Interviews lasted approximately 90 minutes; and respondents were compensated $\$ 30$ for their time.

\section{Measures Used}

The main independent variable used in these analyses is a categorical measure that combines gender and early-life sexual abuse history, dividing respondents into four categories: (1) men who never had been sexually abused during childhood and/or adolescence, (2) men who had been sexually abused during their formative years, (3) women who never had been sexually abused during childhood and/or adolescence, and (4) women who had been sexually abused during their formative years. Information about sexual abuse experiences came from the Childhood Trauma Questionnaire and was collapsed into "experienced" or "never experienced" for analytical purposes [56]. Although it is not being used in scale form here, the original sexual abuse scale used to create this categorical measure was found to be highly reliable (Cronbach's alpha $=0.94$ ).

The principal dependent measure used in these analyses is a continuous measure indicating the proportion of all sex acts that involved the use of male condoms during the 30 days prior to interview. This measure combines oral sex, anal sex, and vaginal sex acts, and is based on behaviors undertaken with all partner types, including main/steady partner(s) and casual partner(s), including persons with whom the respondent had engaged in transactional sex. Scores on this measure ranged from 0 (indicating no use of protection during sex during the preceding month; $38.0 \%$ of participants) to 1 (indicating all sex acts were protected; $22.3 \%$ of participants) (mean $=0.403, \mathrm{SD}=0.413$ ).

As Figure 2 depicts, condom use self-efficacy was used as the main endogenous measure in these analyses. Included in this scale are such items as "I feel confident I could purchase condoms without being embarrassed" and "I feel confident in my ability to put a condom on myself or my partner" and "I would not feel confident suggesting using condoms with a new partner because I would be afraid he/she would think I am too sexually active," among others. This continuous scale measure was comprised by 13 items, all scored with five-point Likert responses ranging from "strongly disagree" to "strongly agree." The scale was adapted from the work done by Brafford and Beck and was found to be reliable (Cronbach's alpha =0.80) [57].

For the multivariate and structural equation analyses undertaken in conjunction with this research, four types of measures were included as independent variables: demographic variables, substance use/abuse measures, measures of psychological/psychosocial functioning, and sexual behaviors or sex-related items (Figure 2).

Demographic variables examined included: gender (coded male versus female), age (continuous), educational attainment (continuous), marital/relationship status (coded as "involved" versus "not involved" in a long- term / romantic relationship), religiosity (continuous), income (continuous), and sexual orientation (dichotomous, comparing heterosexuals to people selfidentifying as gay, lesbian, or bisexual).

Substance use/abuse measures examined in these analyses included: whether or not the person reported drinking alcohol to the point of intoxication during the previous 30 days (yes/no), amount of alcohol consumed during the previous 30 days (continuous, based on quantity $\times$ frequency of alcohol use), age of first use of alcohol (continuous), age of first use of illegal drugs (continuous), the number of types of illegal drugs used during the preceding 30 days (continuous, ranging from 0 to 10), the number of drugrelated problems experienced during the past 30 days (continuous scale measure, Kuder-Richardson ${ }_{20}=0.94$ ), and amount of illegal drug use during the previous 30 days (continuous, based on summing quantity $\times$ frequency of use of 10 types of illegal drugs inquired about).

\footnotetext{
${ }^{3}$ The informed consent form specified all domains of inquiry that were included in the questionnaire, including all forms of abuse and neglect during childhood and adolescence, as well as traumatic and life-threatening events occurring during adulthood. Interviewers prepared (i.e., "braced") respondents for those questions as they reached the appropriate parts of the interview prior to starting those sections, to minimize their potential discomfort with those questions. Participants who expressed concern about these questions were given the option to skip the section(s) in question. It is noteworthy that none of them availed themselves of that option. To take respondents' feelings into account even further, anyone who became upset during the interview was offered a break in the interview before deciding whether or not to continue with the interview. Again, nobody opted to terminate the interview or to skip any of the maltreatment-related questions. Upon completed of their interviews, the well-trained People and Places staff allowed respondents to speak with them in more detail, if they so desired, while also making it clear that they were research staff and not professionally trained to offer the kind of counseling that might be needed. Based on each participant's interest, interviewers provided relevant written material and offered referrals to specific services in the community where the person could receive appropriate help by specially-trained personnel. As appropriate and necessary, staff members offered respondents the referral information so that they themselves could make these inquiries or, if the respondent preferred, the People and Places staff member offered to place the telephone call himself/herself to set up an appointment for the study participant. Very few such referrals were requested over the course of the study.
} 
Four measures of psychological/psychosocial functioning were examined too. These continuous scale measures were: depression (20 items; assessed via the Center for Epidemiologic Studies-Depression [CES-D] scale, Radloff; Cronbach's alpha =0.86), impulsiveness or sensation seeking (12 items; taken from Zuckerman-Kuhlman Personality Questionnaire, Zuckerman; Cronbach's alpha = 0.70), self-esteem (10 items; assessed via the Rosenberg Self-Esteem Scale, Rosenberg; Cronbach's alpha $=0.82)$, and randomness or viewing life events as happening beyond one's own control (7 items; adapted from work by CESSI / Institute for Comparative Social Research; for further details, see www.cessi.ru/index.php?id=140\&L=1; Cronbach's alpha =0.73) [58-60].

Several sexual behavior and sex-related measures were examined in these analyses, too. They included: the number of sex partners during the previous 30 days (continuous), whether or not the person reported having had any casual sex partners during the prior 30 days (yes/no), whether or not the person reported having had any paying sex partners during the previous 30 days (yes/no), age of first sexual intercourse (continuous), number of HIV-infected persons known to the respondent (continuous), number of people known to the respondent who had died from AIDS (continuous), and HIV/AIDS knowledge (continuous scale measure, Kuder- Richardson ${ }_{20}=0.83$ ).

\section{Statistical Analysis}

The first step in the analysis (undertaken to examine the first two research questions posed) was to examine whether or not the combined sexual-abuse-by-gender variable was related either to the endogenous condom use self-efficacy measure and/or to the principal outcome measure, proportion of sex acts involving the use of protection. This was done by conducting analysis of variance (ANOVA) tests for both measures, applying post hoc paired-comparisons tests for any measure showing statisticallysignificant main effects.

The next step in the analysis entailed conducting bivariate analyses for the various independent variables described above as they related to the (un)protected sex outcome measure. Whenever the independent variable in question was dichotomous (e.g., gender, had any recent casual sex partners), these bivariate analyses entailed the use of Student's $t$ tests. Whenever the independent variable in question was continuous (e.g., age, number of drug types used), the bivariate analyses entailed the computation of correlation coefficients, using Pearson's $r$ as the test statistic. Items that were found to be statistically significant $(p<.05)$ or marginally significant $(p<.10)$ in these bivariate analyses were retained for entry into a multiple regression equation to determine which items were associated with the outcome measure when the effects of the other measures under consideration were taken into account. Both forward selection and backward elimination procedures were used to develop a fully-reduced (or saturated) model containing only statistically-significant predictors. The results obtained did not differ based on the selection / elimination approach used. Subsequently, the same procedures just described were followed using condom use self-efficacy (the model's endogenous measure) as the dependent variable.

The final step in the analysis was to map out the findings of the two multiple regression equations in the form of a chart and then subject these findings to a structural equation analysis (Figure 2). When conducting such an analysis to evaluate the overall suitability of the model, we look for four specific parameters to be met. First, the overall goodness-of-fit index should be as close to 1.00 as possible, but not less than 0.90 . Second, the chi-square test for the model should be statistically non-significant, and preferably as far as possible from demonstrating statistical significance. Third, the root mean square error approximation (RMSEA) must be as close to 0.00 as possible, but not greater than 0.05 . Fourth, the Bentler-Bonett coefficient for the normed fit index should be as close to 1.00 as possible, but not less than 0.90 . If all four of these parameters are met, then the structural equation model is said to be a valid, statistically defensible representation of the relationships being examined.

\section{Results}

\section{Sample Characteristics}

Table 1 presents an overview of the characteristics of the sample. Most (56.2\%) of the study participants were male. Respondents ranged in age from 18 to 92 , with a median age of 37 years (mean $=37.3, \mathrm{SD}=13.1$ ). The mean number of years of education was $12.4(S D=2.2$, range $=5-21)$. Nearly one-half of the sample had no more than a high school education (49.3\%). Approximately twothirds of the study participants (69.5\%) were unemployed at the time of interview. Slightly more than one-half of the respondents (55.6\%) were married or involved with someone in a marital-type relationship. As stated earlier, all participants in the People and Places study were African American.

\section{Sexual Abuse and Gender, and (Un)protected Sex and Condom Use Self-Efficacy}

Figure 3 presents the findings obtained for the relationships between sexual abuse and gender, and (un)protected sex and condom use self-efficacy. The left side of the figure shows that the combination of sexual abuse history and gender did have an impact on the extent to which people reported using condoms $(p<.05)$. Post hoc paired-comparisons tests revealed that condom use rates were significantly higher for men who had never been sexually abused when compared to their female counterparts who had been sexually abused during their formative years $(43.3 \%$ versus $35.2 \% ; p<.01)$. The right side of Figure 3 demonstrates that 
the combination of childhood sexual abuse and gender also had a significant impact upon respondents' levels of condom use self-efficacy $(p<.0001)$. Post hoc paired-comparisons tests revealed that women, regardless of their sexual abuse history, reported higher rates of condom use self-efficacy than their male counterparts, also regardless of their sexual abuse history (40.9 versus $39.2 ; p<.0001)$.

\begin{tabular}{|c|c|c|}
\hline Demographic Characteristic & $\mathbf{N}$ & $\%$ of Sample \\
\hline \multicolumn{3}{|l|}{ Gender } \\
\hline Male & 1047 & 56.2 \\
\hline Female & 817 & 43.8 \\
\hline \multicolumn{3}{|l|}{ Age } \\
\hline $18-29$ & 68 & 36.5 \\
\hline $30-39$ & 31 & 17.1 \\
\hline $40-49$ & 45 & 24.5 \\
\hline 50 or older & 409 & 21.9 \\
\hline \multicolumn{3}{|c|}{ Educational Attainment } \\
\hline Less than high school & 732 & 39.1 \\
\hline High school graduate or equivalent & 722 & 38.5 \\
\hline At least some college & 419 & 22.4 \\
\hline \multicolumn{3}{|c|}{ Employment Status* } \\
\hline Unemployed & 1295 & 69.5 \\
\hline Employed, part-time & 243 & 13.0 \\
\hline Employed, full-time & 161 & 8.6 \\
\hline \multicolumn{3}{|c|}{ Marital Status ${ }^{*}$} \\
\hline Single, not married & 737 & 39.5 \\
\hline Married or "involved" in a relationship & 1037 & 55.6 \\
\hline
\end{tabular}

* For these particular measures, the percentages do not add up to $100 \%$ because of other categories not shown in the table Table 1: Demographic Composition of the Sample

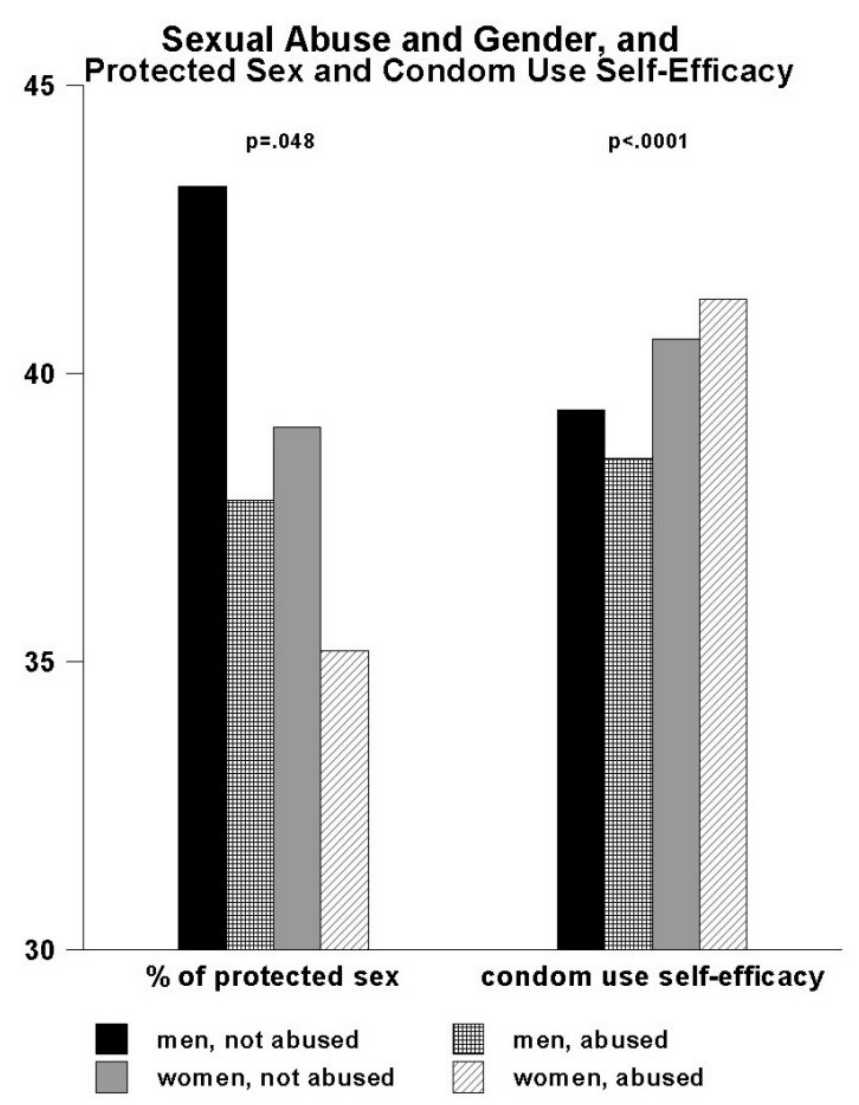

Figure 3: Sexual Abuse, Gender, and HIV Risk Behaviors 


\section{Factors Associated with Protected Sex}

In the interest of conserving space and not bogging down readers with a great deal of extraneous data, the results of the bivariate analyses for both the protected sex outcome measure and the condom use self-efficacy endogenous measure are not presented. As Figure 4 demonstrates, the multivariate analysis identified eight variables that were found to be associated with engaging in protected sex. First, the younger someone was, the more likely he/she was to use condoms $(p<.05)$. Second, people who were married or involved with someone in a marital- type relationship reported less condom use than their unmarried counterparts $(p<.001)$. Third, respondents who had the highest levels of condom use self-efficacy were those who reported the greatest use of condoms $(p<.001)$. Fourth, the higher people's levels of self-esteem were, in general, the more likely they were to use condoms $(p<.001)$. Fifth, the older people were when they had sexual relations for the first time, the more likely they were to report condom use now $(p<.05)$. Sixth, the more HIV-infected persons that the study participant knew, the greater his/her use of sexual protection tended to be $(p<.01)$. Seventh, somewhat counter intuitively, the more involved the person was in polydrug use during the recent past, the more he/she typically engaged in protected rather than unprotected sex $(p<.05)$. Finally, the sexual-abuse-and-gender measure that is used as the focal point of this paper was found to be discerning for engaging in (un)protected sex as well ( $p<.001$ ). Together, these items accounted for $15.6 \%$ of the total variance, with marital status, condom use self-efficacy, level of self-esteem, and the sexual-abuse-and-gender measure being the most salient contributors.

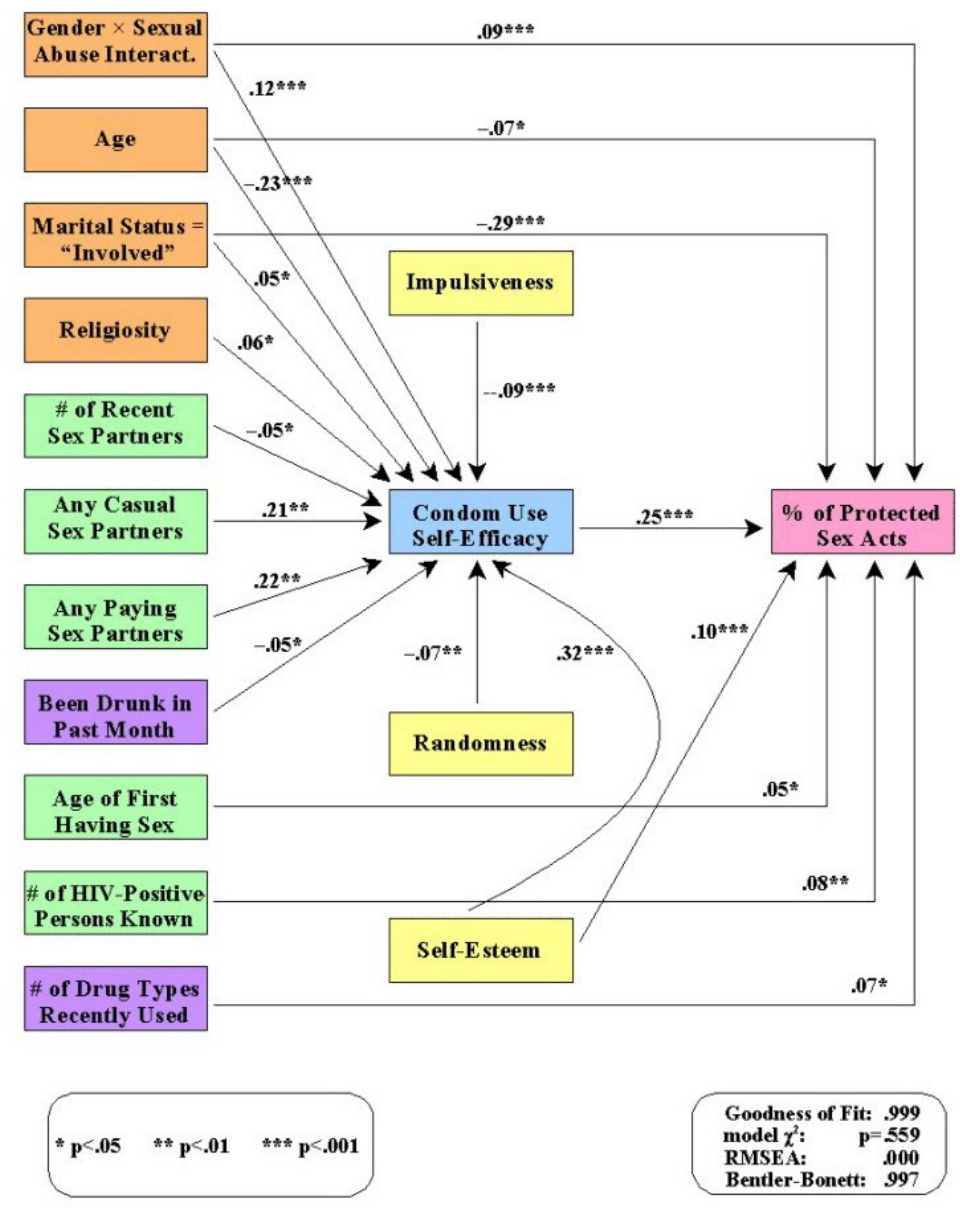

Figure 4: Structural Equation Model for the Factors Associated with Protected Sex

\section{Factors Associated with Condom Use Self-Efficacy}

As Figure 4 depicts, multivariate analysis revealed that 11 items were related to study participants' levels of condom use selfefficacy. First, the younger the person was, the more likely he/she was to feel confident in his/her ability to use condoms correctly and/or to negotiate successfully with a sex partner for their use $(p<.001)$. Second, people who were married or involved with someone in a marital-type relationship reported lower levels of condom use self- efficacy than their unmarried peers $(p<.05)$. Third, the more religious a respondent was, the higher he/she tended to score on the condom use self-efficacy measure $(p<.05)$. Fourth, the greater the number of sex partners that someone reported having during the recent past, the less confident he/she was in his/her ability to use condoms or to negotiate successfully for their use $(p<.05)$. Fifth and sixth, respondents who acknowledged having had any casual sex partners or any paying sex partners during the recent past tended to report higher overall levels of 
condom use self-efficacy than their counterparts who had not had these types of sex partners recently ( $p<.01$ in both instances). Next, study participants who said that they had consumed alcohol to the point of intoxication during the previous month reported lower levels of condom use self-efficacy than their not-recently-intoxicated peers $(p<.05)$. Eighth, the more impulsive people were by nature, the lower their levels of condom use self-efficacy tended to be $(p<.001)$. Ninth, the more that people tended to ascribe events happening to them to outside forces instead of to themselves, the less confident they felt in their ability to use condoms correctly/consistently or to negotiate for their use $(p<.01)$. Tenth, higher self-esteem was associated with greater condom use selfefficacy $(p<.001)$. Finally, the sexual-abuse-and-gender variable (which is the main measure of interest in the present paper) was also found to be one of the unique contributors to respondents' levels of condom use self-efficacy $(p<.001)$. Together, these items accounted for $26.2 \%$ of the total variance, with age, level of impulsivity, level of self-esteem, and the sexual-abuse-and-gender measure being the most salient contributors.

\section{Structural Equation Model}

As a final analytical step, the relationships just described, which are portrayed in Figure 4, were subjected to a structural equation analysis to determine how effective this way of construing the data is. As presented in the lower right-hand corner of Figure 4, the goodness-of-fit index for this model is 0.999 . The chi-square test statistic for the overall equation was found to be nonsignificant, at $p=.559$. The root mean square error approximation for this model is 0.000 . The Bentler-Bonett normed fit index coefficient is 0.997. Overall, these characteristics indicate an excellent fit of the model with the research data, suggesting that Figure 4 is an effective way of representing the relationships within the People and Places study's data.

\section{Discussion}

In this urban-based study of African American adults, both gender and sexual abuse during the formative years, interacting with one another, were related to HIV risk taking. As the present authors have demonstrated in other papers based on very different research samples, the relationship between childhood maltreatment history and HIV risk taking in adulthood is a complex one that does not lend itself to a simplistic or "neat" interpretation $[61,62]$. In the present paper, the primary intergroup difference identified in the multivariate analysis, which was confirmed in the subsequent structural equation analysis, was between men who had not been sexually abused during their formative years and women who had been sexually abused during their formative years, with the latter engaging in protected sex less frequently than the former. In part, this finding is consistent with other studies that have demonstrated a link between sexual abuse and subsequent involvement in higher rates of HIV risk taking among African American women [18,63]. This finding is not consistent with others reported in the scientific literature, however, with regard to the impact of sexual abuse experiences on HIV risk practices among men, which generally have shown that sexual abuse adversely impacts men's lives and health behaviors in subsequent years [64-66].

This leaves us with a conundrum: Why is it that, in the People and Places research sample, HIV risk would be elevated for sexually abused women but not sexually abused men? We have no ready answer to this question, and believe that it is a finding meriting further scientific study. In general, although the impact of sexual abuse on later-life functioning and behaviors has been studied fairly extensively, potential gender differences in this relationship have not been examined much at all. It is possible that sexual abuse affects men and women somewhat differently, not in terms of having adverse effects on them, but rather, in terms of exactly what types of adverse effects it has and how the abuse-related damage manifests itself later in life. This would be an ideal avenue for future researchers to pursue. Nowhere is this more true than with regard to learning more about sexual abuse experiences among African Americans, whose race/ethnicity-specific reactions to experiencing sexual abuse have barely been studied at all, especially in comparison with other racial/ethnic groups. Our hypothesis going into this research, based on previously-published studies addressing masculinity norms among African American men, was that sexually abused men would fare far worse than others in the study in terms of their HIV-related outcomes. This hypothesis was not supported by the data.

Another noteworthy finding coming from this study pertained to the way that the sexual-abuse-and-gender measure related to condom use self-efficacy. This is important, because in the present study, consistent with other published reports condom use selfefficacy was one of the strongest predictors of the use/nonuse of condoms [67-69]. In this research, we found that sexually-abused and never-abused women alike reported higher levels of condom use self-efficacy than their male counterparts, regardless of their sexual abuse histories. This is inconsistent with other research (which has been quite limited) examining gender differences in condom use self-efficacy, which has found greater condom use self-efficacy among men than among women [70]. It is also generally inconsistent with the similarly-limited published research examining the impact of sexual abuse on condom use selfefficacy, which has reported diminished efficacy among people who had been abused while growing up [71].

Once again, we are left in the position of trying to explain unexpected findings regarding the way sexual abuse history and gender interact with one another in terms of their impact on yet another measure that is related closely to HIV risk taking (namely, condom use self-efficacy). Why it is that women in People and Places reported higher levels of condom use self-efficacy than their male counterparts, and why was sexual abuse history not more relevant in this relationship? These are challenging questions to answer. Regarding the latter question, perhaps the psychological damages done by sexual abuse are such that they tend to affect 
other aspects of people's lives more than the confidence they have in their ability to use condoms correctly/consistently and/or to negotiate successfully for their use. That is to say, perhaps sexual abuse is not as salient to condom use self-efficacy as other factorssuch as gender, relationship status, and partner communication skills, for example-are. This is a finding that merits replication in future research, and it is a subject matter (i.e., the extent to which sexual abuse and other types of childhood maltreatment impact condom use self-efficacy) that warrants further examination in future studies.

With respect to the issue of why women in the present study reported higher levels of condom use self-efficacy than men did, there are several possible explanations. One possibility is that more of the sexual decision-making power rests with the African American women interviewed in conjunction with this research than it does with their male counterparts. Other authors have written about sexual empowerment and the factors associated with greater/lesser sexual empowerment among African American women [72-74]. Their works offer some interesting insights and thoughts on the nature of sexual empowerment and issues pertaining to sexual safety / risk taking among African American women; and that might help to explain the gender difference we observed in condom use self-efficacy levels [75]. Another possible explanation for our finding is that the women who participated in this study, more than their male counterparts, have been educated about HIV and the ways to prevent its transmission. There is evidence in the scientific literature to suggest that African American men are in need of additional information, skills training, and intervention/prevention efforts with respect to HIV risk behaviors [76-78]. Thus, it is possible that the men in the People and Places study were more in need of these types of HIV-related information/services than the women, which might help to account for the gender-based difference in condom use self-efficacy levels that we observed. A third possible explanation for our finding is that partner communication skills pertaining to condom use-which is a key component of overall condom use self-efficacy-might be stronger among women than among men. Once again, the published literature contains some evidence to support this notion, as other researchers have reported that women are able to communicate more easily with their partners than men are, although there is also evidence that men are more comfortable discussing sexual matters with their sex partners than women are and some evidence to suggest that African American women oftentimes fail to discuss condom-related matters with their sex partners [7983]. Some women, especially those who are younger adults, may be more willing to discuss sexual matters and condom use with their partners because of concerns surrounding becoming pregnant [84]. Following years of news reports to the general public about rising rates of HIV infections among women at the time this study was conducted, especially among women of color, it is also possible that our female study participants made it a point to try to speak with their sex partners about sexual protectionrelated matters in an effort to keep themselves safe from HIV and other sexually transmitted infections [85].

As one final point of discussion, we would like to highlight the fact that, as we initially hypothesized, the way that sexual abuse history and gender interact with one another and subsequently affect HIV risk taking in this population of urban-resident African Americans was complex. As the conceptual model provided in Figure 2 depicted and as the results obtained and portrayed in Figure 4 demonstrated, the interaction of sexual abuse and gender is but one among many types of factors influencing people's involvement in HIV risk practices. Various aspects of psychological/psychosocial functioning were also relevant. So, too, were study participants' substance use practices, their sexual behaviors, and a variety of demographic characteristics.

How these types of influences-and other factors that were not examined in the present study- work together to determine people's actual sexual risk behaviors is an intricate process that, despite years of scientific inquiry, remains partly unknown, partly notwell-understood, and partly difficult to explain. It is against this backdrop of complicated, intertwined, mutually-influencing relationships that Syndemics Theory-one of the guiding paradigms for the present research-was developed. The findings presented in this paper support the continued use of Syndemics Theory-based research in the study of HIV risk practices. This theoretical approach has grown in popularity during the past 10 to 15 years, and it has been shown in several studies based on quite-varied research samples-including Internet-using men who have sex with other men, young transgender women, South African women attending public drinking venues, patients attending an urban STD clinic, adult women of Latina descent, among others-to be an effective and apropos way of conceptualizing the way that the myriad factors that affect HIV risk taking interact with one another [10,85-90]. The present study's findings extend this trend by demonstrating yet one more population group-namely, urban-dwelling socioeconomically-disadvantaged African Americans-whose risk practices may become better understood with the continued adoption of this theoretical model by future intervention and prevention programs.

\section{Potential Limitations}

We would like to acknowledge a few limitations of these data. First, the data collected as part of this study were all based on uncorroborated self-reports. Therefore, the extent to which respondents underreported or overreported their involvement in risky behaviors is unknown. In all likelihood, the self-reported data can be trusted, as numerous authors have noted that persons in their research studies (which, like the present study, have included fairly large numbers of substance abusers and/or persons at risk for contracting or transmitting HIV) have provided accurate information about their behaviors $[41,91,92]$.

A second possible limitation pertains to recall bias. Respondents were asked to report about their beliefs, attitudes, and behaviors during the past 30 days, the past 90 days, and the past year, depending upon the measure in question. These time frames were chosen specifically (1) to incorporate a large enough amount of time in the risk behavior questions' time frames so as to facilitate meaningful variability from person to person, and (2) to minimize recall bias. The exact extent to which recall bias affected the 
data cannot be assessed although other researchers collecting data similar to that captured in this study have reported that recall bias is sufficiently minimal that its impact upon study findings is likely to be small, provided that the recall period for many types of frequency-counted behaviors does not exceed 90 days [93,94].

A third possible limitation of these data comes from the sampling strategy used. All interviews were conducted in the Atlanta, Georgia metropolitan area. There may very well be local or regional influences or subcultural differences between these women and those residing elsewhere that could affect the generalizability of the data. Additionally, this study was based only on African Americans. Findings may be different amongst members of other racial/ethnic groups. Similarly, there was a residential stability requirement imposed on eligibility for this study. In all likelihood, this has some effect on the data because people who were new to the communities in question and those who had lived in these communities for months or years but who relocated prior to the data collection period would not be included in this study.

Additionally, we would like to acknowledge the fact that different sexual practices carry with them varying levels of actual HIV risk [95]. In the construction of our "proportion of unprotected sex acts" dependent measure, we combined unprotected oral sex, unprotected vaginal sex, and unprotected anal sex so that our analysis was simplified and easy to interpret rather than parsing these behaviors and complicating the results by reporting separately on oral, vaginal, and anal sex. It should be noted, however, that engaging in unprotected anal sex has a much higher risk for transmitting HIV than engaging in unprotected vaginal sex does, and likewise, that vaginal sex is considered to be riskier than oral sex [96-98]. Moreover, the risks for becoming HIV infected through these different types of sexual practices have been shown to differ for men and for women and the measure used in the present study did not take into account those differing levels of exposure-related risk [97].

\section{References}

1. Owens GP, Chard KM (2003) Comorbidityand psychiatricdiagnoses amongwomen reporting child sexual abuse. Child Abuse Negl 27 : 1075-82.

2. Sciolla A, Glover DA, Loeb TB, Zhang M, Myers HF, et al. (2011) Childhood sexual abuse severityand disclosureas predictors of depression amongadult AfricanAmerican and Latina women. J Nerv Ment Dis 199: 471-7.

3. Bedi S, Nelson EC, Lynskey MT, McCutcheon VV, Heath AC, et al. (2011) Risk for suicidal thoughts and behavior after childhood sexual abuse in women and men. Suicide Life Threat Behav 41: 406-15.

4. Easton SD, Renner LM, O'Leary P (2013) Suicide attempts among men with histories of child sexual abuse: Examining abuse severity, mental health, and masculine norms. Child Abuse Negl 37: 380-7.

5. Hill TD, Kaplan LM, French MT, Johnson RJ (2010) Victimization in early life and mental health in adulthood: an examination of the mediating and moderating influences of psychosocial resources. J Health Soc Behav 51: 48-63.

6. Reiland S, Lauterbach D (2008) Effects of trauma and religiosity on self-esteem. Psychol Rep 102: 779-90.

7. Aosved AC, Long PJ, Voller EK (2011) Sexual victimization and adjustment in college men. Psychology Men and Masculinity 12: 285-96.

8. Bailey HN, DeOliveira CA, Wolfe VV, Evans EM, Hartwick C (2012) The impact of childhood maltreatment history on parenting: a comparison of maltreatment types and assessment methods. Child Abuse Negl 36: 236-46.

9. Graham N, Kimonis ER, Wasserman AL, Kline SM (2012) Associations among child abuse and psychopathy facets in male sexual offenders. Personal Disord 3: $66-75$.

10. Steiger H, Richardson J, Schmitz N, Israel M, Bruce KR, et al. (2010) Trait- defined eating-disorder subtypes and history of childhood abuse. Int J Eat Disord 43: 428-32.

11. Wonderlich SA, Rosenfeldt S, Crosby RD, Mitchell JE, Engel SG, et al. (2007) The effects of childhood trauma on daily mood lability and comorbid psychopathology in bulimia nervosa. J Trauma Stress 20: 77-87.

12. Christopher K, Lutz-Zois CJ, Reinhardt AR (2007) Personality pathology as amediator of the relationship between childhood sexual abuse history and sexual abuse. Child Abuse Negl 31: 871-83.

13. Dunkel CS, Mathes E (2012) The role of life history strategy in the correspondence between being a victim and a perpetrator of sexual coercion. J of Evolutionary Psychol 10: 135-47.

14. Sartor CE, McCutcheon VV, Nelson EC, Duncan AE, Bucholz KK, et al. (2012). Investigating the association between childhood sexual abuse and alcohol use disorders in women: does it matter how we ask about sexual abuse? J Stud Alcohol Drugs 73: 740-8.

15. Senn TE, Carey MP, Vanable PA (2010) The Intersection of Violence, Substance Use, Depression, and STDs: Testing of a Syndemic Pattern among Patients Attending an Urban STD Clinic. J Natl Med Assoc 102: 614-20.

16. Hodgins DC, Schopflocher DP, El-Guebaly N, Casey DM, Smith GJ, et al. (2010) The association between childhood maltreatment and gambling problems in a community sample of adult men and women. Psychol Addict Behav 24: 548-54.

17. Petry NM, Steinbert KL (2005) Childhood maltreatment in male and female treatment-seeking pathological gamblers. Psychol Addict Behav 19: 226-9.

18. Senn TE, Carey MP, Coury Doniger P (2012) Mediators of the relation between childhood sexual abuse and women's sexual risk behavior: a comparison of two theoretical frameworks. Arch Sex Behav 41: 1363-77.

19. Hopper J (2016) Child abuse: Sexual abuse of boys: Potential long-term effects.

20. O'Leary P, Easton SD, Gould N (2015) The Effect of Child Sexual Abuse on Men Toward a Male Sensitive Measure. J Interpersonal Violence. doi: $10.1177 / 0886260515586362$

21. How unwanted or abusive sexual experiences can cause problems.

22. Martin G, Bergen HA, Richardson AS, Roeger L, Allison S (2004) Sexual abuse and suicidality: Gender differences in a large community sample of adolescents. Child Abuse and Negl 28: 491-503.

23. Australian Institute on Family Studies (2013) The long-term effects of child sexual abuse: Genderdifferences in the long-term impacts of child sexual abuse and gaps in understandings of male victims/survivors. Child Community Family Australia paper number 11. 
24. Caldwell JE, Swan SC, Woodbrown VD (2012) Gender differences in intimate partner violence outcomes. Psychology of Violence 2: $42-57$.

25. Jewkes R (2010) Emotional abuse: a neglected dimension of partner violence. Lancet 376: 851-2.

26. Ross JM (2012) Self-reported fear in partner violent relationships: Findings on gender differences from two samples. Psychology of Violence 2: 58-74.

27. Haydon AA, Hussey JM, Halpern CT (2011) Childhood abuse and neglect and the risk of STDs in early adulthood. Perspect Sex Reprod Health 43: 16-22.

28. Senn TE, Carey MP (2010) Child maltreatment and women's adult sexual risk behavior: Childhood sexual abuse as a unique risk factor. Child Maltreat 15: 324-35.

29. Hammond, W Powell, Matthis, Jacqueline S (2005) Being a man about it: Manhood meaning among African American men. Psychology of Men and Masculinity 6: 114-26.

30. LaSala MC, Frierson DT (2012) African American Gay Youth and Their Families: Redefining Masculinity, Coping with Racism and Homophobia. J GLBT Family Studies 8: 428-45.

31. Lease SH, Hampton AB, Fleming KM, Baggett LR, Montes SH, et al. (2010) Masculinity and interpersonal competencies: Contrasting white and African American men. Psychology of Men and Masculinity 11: 195-207.

32. Bowleg L (2004) Love, Sex, and Masculinity in Sociocultural Context: HIV Concerns and Condom Use among African American Men in Heterosexual Relationships. Men and Masculinities 7: 166-86.

33. Corneille M, Fife JE, Belgrave FZ, Sims BC (2012) Ethnic identity, Masculinity, and Healthy Sexual Relationships Among African American Men. Psychology of Men and Masculinity 13: 193-9.

34. Crook T, Thomas CM, Cobia DC (2009) Masculinity and Sexuality: Impact on Intimate Relationships of African American Men. The Family J 17: $360-6$.

35. McGuffey CS (2008) 'Saving masculinity': Gender Reaffirmation, Sexuality, Race, and Parental Responses to Male Child Sexual Abuse. Social Problems 55: 216-37.

36. Malebranche DJ, Fields EL, Bryant LO, Harper SR (2009) Masculine Socialization and Sexual Risk Behaviors among Black Men Who Have Sex with Men. A qualitative exploration 12: 90-112.

37. Clear PJ, Vincent JP, Harris GE (2006) Ethnic differences in symptom presentation of sexually bused girls. J Child Sex Abus 15: 79-98.

38. Walsh JL, Senn TE, Carey MP (2012) Exposure to Different Types of Violence and Subsequent Sexual Risk Behavior among Female STD clinic patients: A Latent Class Analysis. Psychol Violence 2: 339-54.

39. Ulibarri MD, Ulloa EC, Camacho L (2009) Prevalence of Sexually Abusive Experiences in Childhood and Adolescence among a Community Sample of Latinas: A Descriptive Study. J Child Sex Abus 18: 405-21.

40. Warner LA, Alegria M, Canino G (2012) Childhood maltreatment among Hispanic women in the United States: an examination of subgroup differences and impact on psychiatric disorder. Child Maltreatment 17: 119-31.

41. NIMH Multisite HIV/STD Prevention Trial for African American Couples Group (2010) Prevalence of Child and Adult Sexual Abuse and Risk Taking Practices Among HIV Serodiscordant African-American Couples. AIDS Behav 14: 1032-44.

42. Lee C, Cronley C, White HR, Mun EY, Stouthamer-Loeber M, et al. (2012) Racial differences in the consequences of childhood maltreatment for adolescent and young adult depression, heavy drinking, and violence. J Adolesc Health 50: 443-9.

43. Cambron C, Gringeri C, Vogel-Ferguson MB (2014) Physical and mental health correlates of adverse childhood experiences among low-income women. Health Soc Work 39: 221-9.

44. Zielinski DS (2009) Child maltreatment and adult socio economic well-being. Child Abuse Negl 33: 666-78.

45. Dunlap E, Golub A, Johnson BD (2003) Girls'sexual development in the inner city: From compelled childhood sexual contact to sex-for-thing sex changes. J Child Sexual Abuse 12: 73-96.

46. Tharp AT, DeGue S, Valle LA, Brookmeyer KA, Massetti GM, et al. (2013) A systematic qualitative review of risk and protective factors for sexual violence perpetration. Trauma Violence Abuse 14: 133-67.

47. Traub SH, Little CB (1999) Theories of deviance $5^{\text {th }}$ edn. Beverly, MA: Wadsworth Publishing.

48. Singer MC (2009) Introduction to syndemics: A critical systems approach to public and community health. SanFrancisco: John WileyandSons.

49. Egan JE, Frye V, Kurtz SP, Latkin C, Chen M, et al. (2011) Migration, neighborhoods, and networks: Approaches to understanding how urban environmental conditions affect syndemic adverse health outcomes among gay, bisexual and other men who have sex with men. AIDS Behav 15: s35-s50.

50. Gardner M, Barajas RG, Brooks-Gunn J (2010) Neighborhood influences on substance use etiology: Is where you live important? In: L. Scheier(Ed.). Handbook of drug use etiology: Theory, methods, and empirical findings. Washington, DC: American Psychological Association 423-41.

51. Martinez R Jr, Rosenfeld R, Mares D (2008) Social Disorganization, Drug Market Activity, and Neighborhood Violent Crime. Urban Aff Rev Thousand Oaks Calif 43: 846-74.

52. Meyer JP, Springer SA, Altice FL (2011) Substance abuse, violence, and HIV in women: a literature review of the syndemic. J Womens Health 20: 991-6.

53. Nielsen AL, Hill TD, French MT, Hernandez MN (2010) Racial/ethnic composition, social disorganization, and offsite alcohol availabilityin San Diego County, California. Soc Sci Res 39: 165-75.

54. Cutrona CE, Russell DW, Brown PA, Clark LA, Hessling RM, et al. (2005) Neighborhood context, personality, and stressful life events as predictors of depression among African American women. J Abnorm Psychol 114: 3-15.

55. Sampson RJ, Raudenbush SW, Earls F (1997) Neighborhoods and violent crime: a multilevel study of collective efficacy. Science 277: 918-24.

56. Bernstein DP, Fink L (1998) Childhood Trauma Questionnaire: A retrospective self- report manual. San Antonio, TX: Psychological Corporation.

57. Brafford LJ, Beck KH (1991) Development and validation of a condom self-efficacy scale for college students. J Am Coll Healthv $39: 219-25$.

58. Radloff LS (1977) The CES-D scale: A self-report depression scale for research in the general population. Psychiatry Res 1: 385-401.

59. Zuckerman M (2002) Zuckerman-Kuhlman PersonalityQuestionnaire(ZKPQ): An alternative five-factormodel. In:B. De Raad\&Perugini (Eds.). Big five assessment. Seattle. WA: Hogrefeand Huber 377-96.

60. Rosenberg M (1965) Society and the adolescent self-image. J Affect Disord. 
61. Klein H, Elifson KW, Sterk CE (2007) Childhood neglect and adulthood involvement in sexual and HIV-related risk behaviors. Child Abuse and Neglect 31: $39-53$.

62. Klein H, Tilley DL (2012) Childhood maltreatment and HIV risk taking among men using the Internet specifically to find partners for unprotected sex. Int Public Health J 4: 33-42.

63. Paxton KC, Myers HF, Hall NM, Javanbakht M (2004) Ethnicity, serostatus, and psychosocial differences in sexual risk behavior among HIV-seropositive and HIV- seronegative women. AIDS Behav 8: 405-15.

64. Artime TM, Peterson ZD (2012) The relationships among childhood maltreatment, emotion regulation, and sexual risk taking among men from urban STD clinics. J Aggress Maltreat Trauma 21: 277-99.

65. Morokoff PJ, Redding CA, Harlow LL, Cho S, Brown-Peterside P (2009) Associations of sexual victimization, depression, and sexual assertiveness with unprotected sex: A test of the multifaceted model of HIV risk across gender. J Appl Biobehav Res 14: 30-54.

66. Reisner SL, Falb KL, Mimiaga MJ (2011) Early life traumatic stressors and the mediating role of PTSD in incident HIV infection among US men, comparisons by sexual orientation and race/ethnicity: Results from the NESARC, 2004-2005. J Acquir Immune Defic Syndr 57: 340-50.

67. Alleyne B (2008) HIV risk behaviors among a sample of young black college women. J HIV AIDS Soc Serv 7: 351-71.

68. O'Leary A, Jemmott LS, Jemmott JB (2008) Mediation analysis of an effective sexual risk-reduction intervention for women: The importanceof self-efficacy. Health Psychol 27: 180-4.

69. Sagrestano LM, Rogers A, Kittleson MJ, Sarvela PD (2005) Does efficacy mediate stage of change and condom use in injected-drug users? Am J Health Behav 29: $12-24$

70. Farmer MA, Meston CM (2006) Predictors of condom use self-efficacy in an ethnically diverse university sample. Arch Sex Behav 35: 313-26.

71. Waymont HA, Aronson B (2002) Risky sexual behavior in American white college women: The role of sex guilt and sexual abuse. J Health Psychol 7: 723-33.

72. Crepaz N, Marshall KJ, Aupont LW, Jacobs ED, O'Leary A (2009) The efficacy of HIV/STI behavioral interventions for African American females in the United States: A meta-analysis. Am J Public Health 99: 2069-78.

73. Long CA, Vance DE, Antia LA (2009) Adescriptive study of empowerment and sexual decision makingin HIV-positive African-American women. Psychol Rep 104: 482-8.

74. Soet JE, Dudley WN, Dilorio C (1999) The effects of ethnicity and perceived power on women's sexual behavior. Psychol Women Q 23: 707-23.

75. Fisher ML, Garcia JR, Chang RS (2013) Evolution's empress: Darwinian perspectives on the nature of women. NewYork: OxfordUniversityPress.

76. Heeren GA, Jemmott JB (2011) Health promotion: Results of focus groups with African-American men. J Mens Health 8: 50-5.

77. Otto-Salaj LL, Traxel N, Brondino MJ, Reed B, Gore-Felton C, et al. (2010) Reactions of heterosexual African American men to women's condom negotiation strategies. J Sex Res 47: 539-51.

78. Williams PB, Sallar AM (2010) HIV/AIDS and African American men: Urban-rural differences in sexual behavior, HIV knowledge, and attitudes toward condom use. J Natl Med Assoc 102: 1139-49.

79. Oberzaucher E (2013) Sex and gender differences in communication strategies. Social Psychology 345-67.

80. Wu C, McLaughlin K (2013) Bridging the gender gap in communication skills. Adv Health Sci Educ 18: 129-31.

81. Zukoski AP, Harvey SM, Branch M (2009) Condom use: Exploring verbal and non- verbal communication strategies among Latino and African American men and women. AIDS Care 21: 1042-9.

82. Montesi JL, Fauber RL, Gordon EA, Heimberg RG (2010) The specific importance of communicating about sex to couples' sexual and overall relationship satisfaction. J Soc Pers Relat 28: 591-609.

83. Foreman FE (2003) African American college women: Constructing a hierarchy of sexual arrangements. AIDS Care 15: 493-504.

84. Siegel DM, Klein DI, Roghmann KJ (1999) Sexual behavior, contraception, and risk among college students. J Adolesc Health 25: $336-43$.

85. Christopher K, Lutz-Zois CJ (2008) Reinhardt AR HIV/AIDS among women-Centers for Disease Control and Prevention. CDC HIV/AIDS fact sheet: Atlanta, GA: Centers for Disease Control and Prevention (2007). Female sexual-offenders.

86. Halkitis PN, Moeller RW, Siconolfi DE, Storholm ED, Solomon TM, et al. (2013) Measurement model exploring a syndemic in emerging adult gay and bisexual men. AIDS and Behavior 17: 662-73.

87. Klein H (2011) Using a syndemics theory approach to study HIV risk taking in a population of men who use the Internet to find partners for unprotected sex. Am J Mens Health 5: 466-76.

88. Brennan J, Kuhns LM, Johnson AK, Belzer M, Wilson EC, et al. (2012) Syndemic theoryand HIV-related risk among young transgender women: The role of multiple, co-occurring health problems and social marginalization. Am J Public Health 102: 1751-7.

89. Pitpitan EV, Kalichman SC, Eaton LA, Cain D, Sikkema KJ, et al. (2013) Co-occurring psychosocial problems and HIV risk among women attending drinking venues in a South African township: A syndemic approach. Ann Behav Med 45: 153-62.

90. Gonzalez-Guarda RM, McCabe BE, Florom-Smith A, Cianelli R, Peragallo N (2011) Substance abuse, violence, HIV, and depression: An underlying syndemic factor among Latinas. Nurs Res 60: 182-9.

91. Jackson CT, Covell NH, Frisman LK, Essock SM (2004) Validity of self-reported drug use among people with co-occurring mental health and substance use disorders. J Dual Diagn 1: 49-63.

92. Napper LE, Fisher DG, Johnson ME, Wood WM (2010) The reliability and validity of drug users' self reports of amphetamine use among primarily heroin and cocaine users. Addict Behav 35: 350.

93. Jaccard J, Wan CK (1995) Measurement error in the analysis of interaction effects between continuous predictors using multiple regression: Multiple indicator and structural equation approaches. Psychological Bulletin 117: 348-57.

94. Graham CA, Catania JA, Brand R, Duong T, Canchola JA (2003) Recalling sexual behavior: A methodological analysis of memory recall bias via interview using the diary as the gold standard. J Sex Res 40: 325-32.

95. Klein H (2014) Condom use self-efficacy and HIV risk practices among men who use the Internet to find male partners for unprotected sex. Am J Mens Health 8: 190-204.

96. Baggaley RF, White RG, Boily MC (2010) HIV transmission risk through anal intercourse: Systemic review, meta-analysis and implications for HIV research. Int J Epidemiol 39: 1048-63. 
97. Patel P, Borkowf CB, Brooks JT, Lasry A, Lansky A, et al. (2014) Estimating per-act HIV transmission: A systematic review. AIDS 28: 1509-19.

98. Wilton J (2012) Putting a number on it: The risk from an exposure to HIV.

99. Blain LM, Muench F, Morgenstern J, Parsons JT (2012) Exploring the role of child sexual abuse and posttraumatic stress disorder symptoms in gay and bisexual men reporting compulsive sexual behavior. Child Abuse Negl 36: 413-22.

100. Welles SL, Corbin TJ, Rich JA, Reed E, Raj A (2011) Intimate partner violence among men havingsex with men, women, or both: Early-life sexual and physical abuse as antecedents. J Community Health 36: 477-85.

101. Fields SD, Malebranche D, Feist-Price S (2008) Childhood sexual abuse in black men who have sex with men: Results from three qualitative studies. Cultur Divers Ethnic Minor Psychol 14: 385-90.

102. Welles SL, Baker AC, Miner MH, Brennan DJ, Jacoby S, et al. (2009) History of childhood sexual abuse and unsafe anal intercourse in a six-city study of HIVpositive men who have sex with men. Am J Public Health 99: 1079-86.

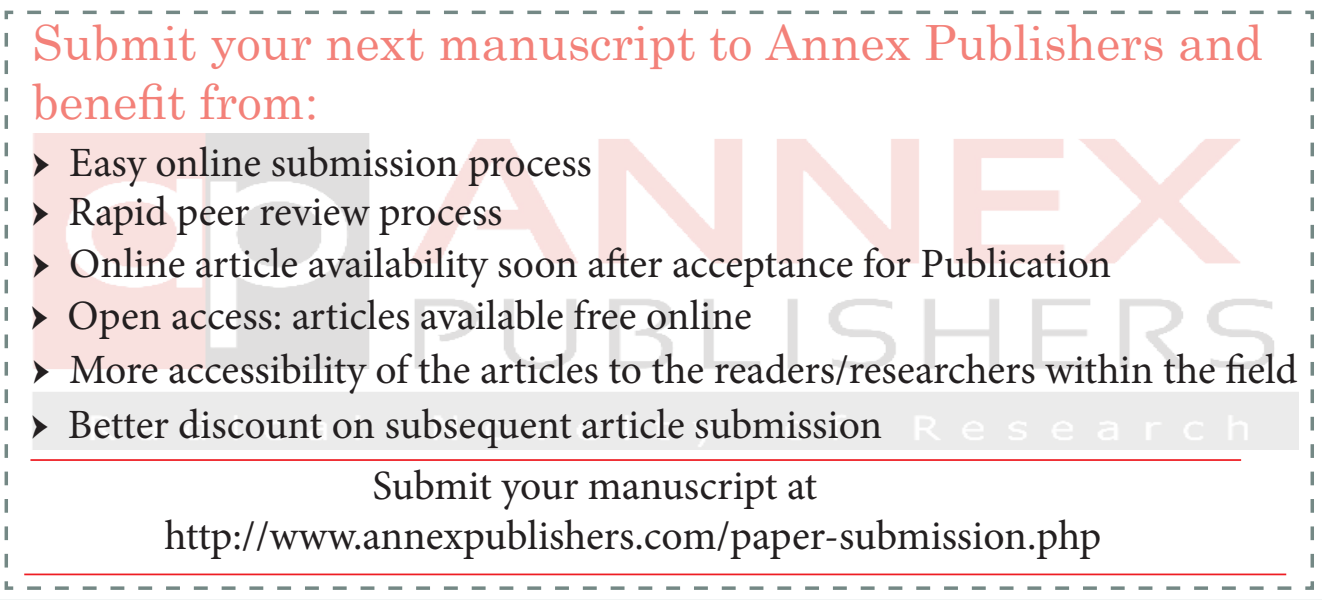

